Urologe 2009 [Suppl 1] · 48:4

DOI 10.1007/s00120-009-2093-2

(c) Springer Medizin Verlag 2009

\title{
M. Wirth
}

Klinik und Poliklinik für Urologie,

Universitätsklinikum Carl Gustav Carus, TU Dresden

\section{Kongress der Deutschen Gesellschaft für Urologie e.V.}

nom erstmalig auf dem Deutschen Urologenkongress präsentiert wird.

Die besondere Kompetenz unseres Fachgebietes wird auch durch die Arbeitskreise demonstriert, die am Mittwochnachmittag einen breiten Raum zur Darstellung ihrer Teilgebiete erhalten haben. Des Weiteren wird Ihnen in insgesamt 3 Plenar- und 20 Forumssitzungen ein, wie wir hoffen, interessanter Querschnitt der Urologie vermittelt. Dabei werden wir auch durchaus ,heiße Eisen“ anfassen.

Bedanken möchte ich mich insbesondere bei unseren wissenschaftlichen Gutachtern, die es auf sich genommen haben, die 878 eingereichten Abstracts zu lesen und zu bewerten. Die Programmkommission hat basierend auf dieser Begutachtung ein sicherlich interessantes Programm erstellt, das für jeden von Ihnen viele wichtige Aspekte enthält.

Insgesamt ist es der Arbeit vieler geschuldet, die sich mit hohem persönlichem Einsatz gekümmert haben, dass wir auch in diesem Jahr einen so umfassenden Abstractband herausgeben können.

Sehr herzlich bedanken möchte ich mich für die hervorragende Unterstützung bei Herrn PD Dr. med. Grimm, Frau Krüger, Frau Dr. med. Rippel, Frau Voigt, Herrn Dr. med. Propping sowie dem gesamten Dresdner Team. Besondere Anerkennung verdienen Herrn Neugebauer und Frau Scharp von der Firma Pharmaservice für das elektronische Abstracthandling.

Einen wichtigen Beitrag leisteten hier auch die Damen und Herren der Geschäftsstelle der Deutschen Gesellschaft für Uro- logie, für deren stete Hilfe ich mich ebenfalls herzlich bedanken möchte.

Das gesamte „Kongressteam Dresden“ freut sich auf Ihren Besuch in der Sächsischen Landeshauptstadt, die als besondere Kunst- und Kulturstadt auch Ihnen sicher gefallen wird. Wir wünschen uns viele gute Gespräche und Begegnungen und einen breiten Informationsaustausch, um unserem obersten Ziel zu dienen, den uns anvertrauten Patienten eine bestmögliche Betreuung zu gewährleisten.

Mit herzlichen Grüßen

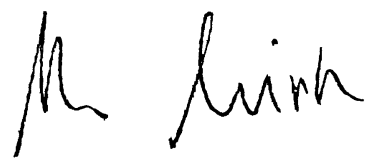

Prof. Dr. med. Dr. h.c. Manfred Wirth Präsident der DGU 2009 